\section{Effect of lipopolysaccharides on vascular endothelial growth factor expression in mouse pulp cells and macrophages}

\author{
Botero TM, Mantellini MG, Song $W$, Hanks CT, Nör JE. Effect of lipopolysaccharides \\ on vascular endothelial growth factor expression in mouse pulp cells and macrophages. \\ Eur J Oral Sci 2003; 111: 228-234. (C) Eur J Oral Sci, 2003 \\ Vascular endothelial growth factor (VEGF), a potent pro-angiogenic factor, might \\ regulate the neovascularization observed in the pulp of teeth with deep caries. The \\ purpose of this in vitro study was to evaluate the effect of bacterial lipopolysaccharides \\ (LPS) on VEGF expression in dental pulp cells. Mouse odontoblast-like cells (MDPC- \\ 23) or undifferentiated pulp cells (OD-21) were exposed to 0-20 $\mu \mathrm{g} \mathrm{ml}^{-1}$ Escherichia \\ coli LPS or 0-80 $\mu \mathrm{g} \mathrm{ml}^{-1}$ Prevotella intermedia LPS. As controls, mouse macrophages \\ or gingival fibroblasts were exposed to LPS, since these cells are known to secrete \\ VEGF. The VEGF expression was evaluated by reverse transcriptase polymerase \\ chain reaction or enzyme-linked immunosorbent assay. The baseline expression levels \\ of VEGF protein were higher in MDPC-23 and OD-21 than in fibroblasts or macr- \\ ophages. Vascular endothelial growth factor protein expression was upregulated in \\ MDPC-23 and macrophages exposed to E. coli LPS, but not in OD-21 cells or \\ fibroblasts. Higher concentrations of $P$. intermedia LPS were required to induce \\ VEGF expression in MDPC-23 cells. Treatment with LPS did not affect VEGF ex- \\ pression at the mRNA level in any of the cells evaluated. These results demonstrate \\ that bacterial LPS upregulates VEGF expression in odontoblast-like cells and macr- \\ ophages, and suggest that the regulation of VEGF expression occurs primarily at a \\ post-transcriptional level.
}

Tatiana M. Botero', Maria G. Mantellini ${ }^{1}$, Wenying Song ${ }^{1}$, Carl T. Hanks ${ }^{2}$, Jacques E. Nör ${ }^{1}$

${ }^{1}$ Department of Cariology, Restorative Sciences, and Endodontics, and ${ }^{2}$ Department of Oral Medicine, Pathology and Oncology, University of Michigan School of Dentistry; Ann Arbor, Michigan, USA

\begin{abstract}
Jacques Eduardo Nör DDS, MS, PhD, University of Michigan School of Dentistry, 1011 North University, Room 5211, Ann Arbor, MI 48109-1078, USA

Telefax: +1-734-9361597

E-mail: jenor@umich.edu

Key words: vascular endothelial growth factor (VEGF); neovascularization; angiogenesis; dental pulp; lipopolysaccharide (LPS)
\end{abstract}

Accepted for publication February 2003
Deep dentinal caries are frequently associated with enhanced pulp vascularization. The initial hemodynamic changes in the capillary and venous network are vasodilatation and increased vascular permeability within the pulp tissue (1). Absorption of interstitial fluid back into the vessels, increased lymph flow, and opening of arteriovenous anastomosis are mechanisms used by the pulp tissue to maintain intrapulpal pressure (2). However, the dental pulp tissue is confined within rigid walls (3) and the pulp tissue pressure tends to increase when it is exposed to continuous noxious stimuli, such as caries. When the intrapulpal pressure passes an unknown threshold, and the local pressure-relief mechanisms are no longer effective, irreversible pulp inflammation or necrosis may occur (4).

The most common cause of pulpitis is cariogenic bacteria and their products (5). Gram-positive bacteria such as Streptococci, Lactobacilli, and several Grampositive rods have been found in carious dentin (6). In the presence of sucrose, caries-related Gram-positive bacteria produce large quantities of lipoteichoic acid (7), an amphiphilic molecule anchored to the bacterial cell wall that has been implicated in inflammation (8). Gramnegative bacteria such as Prevotella and Porphyromonas have also been found in teeth with dentinal caries and symptoms of reversible pulpitis (9-11), and in teeth with deep caries and/or pulp exposure with irreversible pulpitis (12). These bacteria play a significant role in the development of clinical symptoms through the production of pro-inflammatory cytokines such as interleukin (IL)-1 $\beta$ (13), IL-6 (14), and IL-8 (15). In contrast to the lipoteichoic acid found in Gram-positive bacteria, the cell wall of Gram-negative bacteria contains lipopolysaccharides (LPS). Lipopolysaccharide is a heat-stable molecule composed of polysaccharides and phospholipids. The hydrophobic component of LPS (lipid A) is embedded in the bacterial cell wall and determines the endotoxin properties of this molecule such as toxicity, pyrogenicity, and macrophage and complement activation (16). The rough core polysaccharide side-chain in the center and the $O$-antigenic side chain in the peripheral area determine serotype specificity (17). The signaling events triggered by LPS in mammalian cells are believed to be initiated upon its binding to a cell surface receptor CD14 $(18,19)$, or to Toll-like receptors (TLRs), primarily TLR-4 and its accessory protein MD2 (20). Activation of these receptors initiates several intracellular signaling pathways that involve MyD88, I- $\kappa$ B kinase 
(IKK), and mitogen-activated protein kinase (MAPK) (21).

Vascular endothelial growth factor (VEGF) is a strong inducer of angiogenesis and is synthesized by macrophages, smooth muscle cells, pericytes, keratinocytes, and several tumor cells (22). It activates endothelial cells and induces angiogenesis during inflammation and wound healing processes (23). The angiogenic activity attributed to VEGF is also a result its ability to enhance endothelial cell survival by inducing expression of the anti-apoptotic protein Bcl-2 (24). Vascular endothelial growth factor enhances the permeability of blood vessels (25), which is an important vascular change observed during pulpitis. It has recently been found in the dentin matrix and its release during caries progression might contribute to the reparative response of pulp-dentinal complex (26).

Bacterial LPS enhances VEGF expression by a mixed population of dental pulp cells in vitro (27) and a recent paper analysed the expression of VEGF in both healthy and inflamed dental pulps in vivo (28). However, it is not known if LPS stimulation has a direct effect on VEGF expression by odontoblasts or undifferentiated pulp cells. The purpose of this in vitro study was to evaluate the effect of bacterial LPS on VEGF expression in mouse odontoblast-like cells and undifferentiated pulp cells, and to compare it with two well-characterized cellular sources of VEGF, namely macrophages and fibroblasts. The test hypothesis was that all cells increase VEGF expression following exposure to LPS.

\section{Material and methods}

\section{Cell culture}

Four mouse cell lines were used in this study: odontoblastlike cells (MDPC-23), undifferentiated pulp cells (OD-21) (29), macrophages (RAW 267.4; ATCC, Manassas, VA, USA), and gingival fibroblasts. The gingival fibroblasts were primary cells isolated with surgical biopsy from mouse gingiva, trypsinized and cultured in T-25 flasks. The isolation of cells and animal care were performed in accordance with institutional guidelines. Cell lines were cultured with Dulbecco's Modified Eagle's medium (DMEM; Gibco BRL, Grand Island, NY, USA), supplemented with 10\% fetal bovine serum (Gibco), $200 \mathrm{~mm}$ L-glutamine (Gibco), 50 -units $\mathrm{ml}^{-1}$ penicillin (Gibco), and $50 \mu \mathrm{g} \mathrm{ml}^{-1}$ streptomycin (Gibco) in a humidified $\mathrm{CO}_{2}$ incubator at $37^{\circ} \mathrm{C}$.

\section{Enzyme-linked immunosorbent assay}

An enzyme linked immunosorbent assay (ELISA) kit (Quantikine Murine VEGF Kit; R \& D Systems, Minneapolis, MN, USA) was used to evaluate the concentration of VEGF ( $\mathrm{VEGF}_{120}$ and $\mathrm{VEGF}_{164}$ isoforms) in the conditioned medium collected from each experimental group after a 24-h exposure to Escherichia coli 055:B5 LPS (Sigma Chemical Co., St. Louis, MO, USA), or to Prevotella intermedia LPS (gift from C. E. Shelburne, University of Michigan, Ann Arbor, MI, USA). Cells were plated in 12 -well plates $\left(4 \times 10^{4}\right.$ cells per well $)$ and allowed to attach overnight. Cell culture medium was changed, and
0-20 $\mu \mathrm{g} \mathrm{ml}^{-1}$ of E. coli LPS or 0-80 $\mu \mathrm{g} \mathrm{ml}^{-1} P$. intermedia LPS were added to the medium. Conditioned medium was collected after $24 \mathrm{~h}$, from 3 wells per condition, and the concentration of VEGF was analysed by ELISA. Recombinant mouse VEGF (R \& D Systems) was used as a positive control. Culture medium alone was used to determine background VEGF expression. The optical density of the samples were measured in a spectrophotometer at $450 \mathrm{~nm}$ (DU-20; Beckman, Fullerton, CA, USA). The data on VEGF concentration was normalized by the number of viable cells at the time of collection of conditioned medium as determined by Trypan Blue assay (30). Data presented here describe the results of one representative experiment selected from at least three independent experiments per condition and cell type.

\section{Semi-quantitative reverse transcriptase polymerase chain reaction}

The MDPC-23, OD-21, gingival fibroblasts, or macrophages were exposed for $24 \mathrm{~h}$ to 0 or $20 \mu \mathrm{g} \mathrm{ml}^{-1} E$. coli LPS, and RNAeasy Mini Kit (Qiagen, Valencia, CA, USA) was used according to the manufacturer's instructions to extract total RNA. Superscript one-step reverse transcriptase polymerase chain reaction (RT-PCR) with Platinum Taq (Invitrogen, Carlsbad, CA, USA) was used for cDNA synthesis and PCR amplification, according to manufacturer's instructions. Briefly, cDNA synthesis and predenaturation were achieved by incubating template RNA (10 ng per sample), $0.2 \mu \mathrm{M}$ sense primer, $0.2 \mu \mathrm{M}$ antisense primer, $0.2 \mu \mathrm{M}$ dNTP, $1.2 \mathrm{~mm} \mathrm{MgSO}_{4}$, and $1 \mu \mathrm{l} \mathrm{RT/Platinum} \mathrm{Taq}$ Mix in a reaction volume of $50 \mu \mathrm{l}$ for $30 \mathrm{~min}$ at $50^{\circ} \mathrm{C}$, then for $2 \mathrm{~min}$ at $94^{\circ} \mathrm{C}$ in a Mastercycler Gradient thermocycler (Eppendorf, Hamburg, Germany). Polymerase chain reaction amplification was performed at $94^{\circ} \mathrm{C}$ for $15 \mathrm{~s}, 55^{\circ} \mathrm{C}$ for $30 \mathrm{~s}$, and $72^{\circ} \mathrm{C}$ for $30 \mathrm{~s}$, for 35 cycles. Final extension of PCR products was achieved by incubation for $5 \mathrm{~min}$ at $72^{\circ} \mathrm{C}$. The PCR was performed using primers designed to amplify all three mouse VEGF isoforms (i.e. $\mathrm{VEGF}_{120}$, $\mathrm{VEGF}_{164}$, and $\mathrm{VEGF}_{188}$ ), with an expected product size for each isoform of 431,563 , and $635 \mathrm{bp}$, respectively $(31,32)$. The VEGF primers were: sense, 5'-CTGCTCTCTTGGGTCCACTGG-3'; and antisense, 5'-CACCGGGTTGGCTTGTCACAT-3' (32). A housekeeping gene, glyceraldehyde adenosine-phosphate dehydrogenase (GAPDH), was used as an amplification internal control for the RT-PCR assays. The GADPH primers were: sense, 5'-CCCACTAACATCAAATGGGG-3'; and antisense, 5'-TTGGCTCCACCACCCTTCAAGT-3'. Amplification conditions were optimized for this experiment to determine concentration of template RNA, number of cycles, and denaturation, annealing, and extension temperature that allowed for gene expression analysis within the linear phase of product amplification. The RT-PCR products were analysed by electrophoresis on $1 \%$ agarose gels stained with ethidium bromide. Gels were photographed with a Polaroid gel camera on an ultraviolet transilluminator screen (Spectroline, Westbury, NY, USA). Data presented is representative of three independent experiments.

\section{Statistical analyses}

Data was analysed by one-way ANOvA followed by Tukey's test, or Student's $t$-tests with SIGMASTAT 2.0 statistical software (SPSS, Chicago, IL, USA). The significance level of the data was determined at $P \leq 0.05$. 


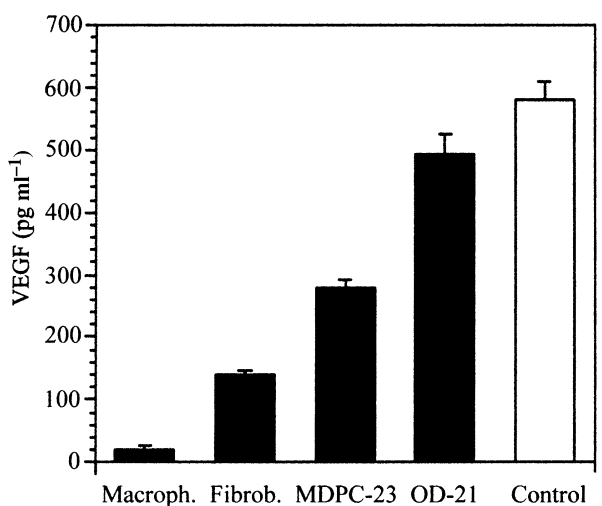

Fig. 1. Baseline vascular endothelial growth factor (VEGF) expression analysed by enzyme-linked immunosorbent assay (ELISA) of conditioned medium collected from untreated macrophages, gingival fibroblasts, MDPC-23 or OD-21. Positive control for ELISA was recombinant mouse VEGF.

\section{Results}

\section{Lipopolysaccharide upregulates VEGF expression in odontoblast-like cells and macrophages}

To evaluate baseline VEGF expression by pulp cells, we performed ELISAs of conditioned medium collected from untreated MDPC-23 or OD-21, and compared these with expression of VEGF in conditioned medium from our control cells, fibroblasts and macrophages. We observed that OD-21 expressed the highest baseline levels of VEGF, followed by MDPC-23, fibroblasts and macrophages (Fig. 1). To evaluate the effect of LPS on VEGF expression in pulp cells, we exposed MDPC-23, OD-21, fibroblasts or macrophages to $0-20 \mu \mathrm{g} \mathrm{ml}^{-1}$ E. coli LPS for $24 \mathrm{~h}$, collected the supernatant and performed ELISA. The Trypan Blue exclusion viability test was used to normalize the data by the number of viable cells per sample. Exposure to $20 \mu \mathrm{g} \mathrm{ml}^{-1}$ E. coli LPS induced upregulation of VEGF expression in MDPC-23 $\left(474.6 \pm 88.9 \mathrm{pg} \mathrm{ml}^{-1}\right)$ compared with the untreated MDPC-23 controls $\left(300 \pm 17.5 \mathrm{pg} \mathrm{ml}^{-1}\right)$ (Fig. 2A). In macrophages, the expression of VEGF was tenfold higher in cells exposed to $20 \mu \mathrm{g} \mathrm{ml}^{-1} E$. coli LPS than in untreated controls (Fig. 2B). In contrast, we did not find any induction of VEGF expression upon exposure of fibroblasts or OD-21 to E. coli LPS (Fig. 2C,D).

Prevotella intermedia is considered one of the predominant bacterial species in dentinal caries (10). To evaluate the effect of this Gram-negative species on VEGF expression, we exposed the cells described above to 0 $80 \mu \mathrm{g} \mathrm{ml}^{-1} P$. intermedia LPS and performed ELISA from conditioned medium. We observed that $P$. intermedia LPS induced VEGF upregulation in MDPC-23, but only when
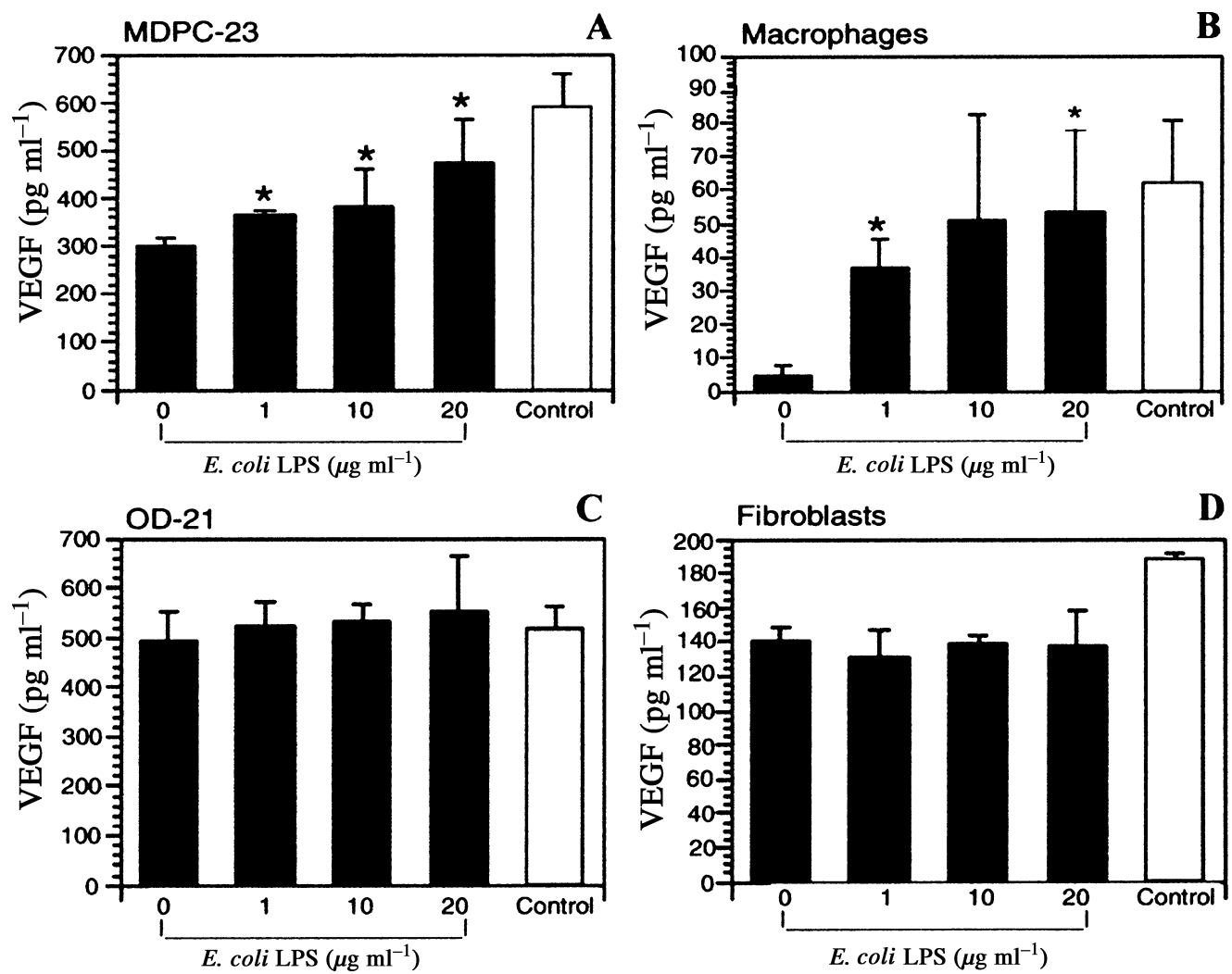

Fig. 2. Escherichia coli lipopolysaccharide (LPS) induces vascular endothelial growth factor (VEGF) expression in odontoblast-like cells (MDPC-23) and macrophages. Expression of VEGF was analysed by enzyme-linked immunosorbent assay (ELISA) of conditioned medium from (A) MDPC-23, (B) macrophages, (C) OD-21, or (D) gingival fibroblasts exposed for $24 \mathrm{~h}^{\text {to }} 0-20 \mu \mathrm{g} \mathrm{ml}{ }^{-1}$ E. coli LPS. Positive control for ELISA was recombinant mouse VEGF. * $P \leq 0.05$. 

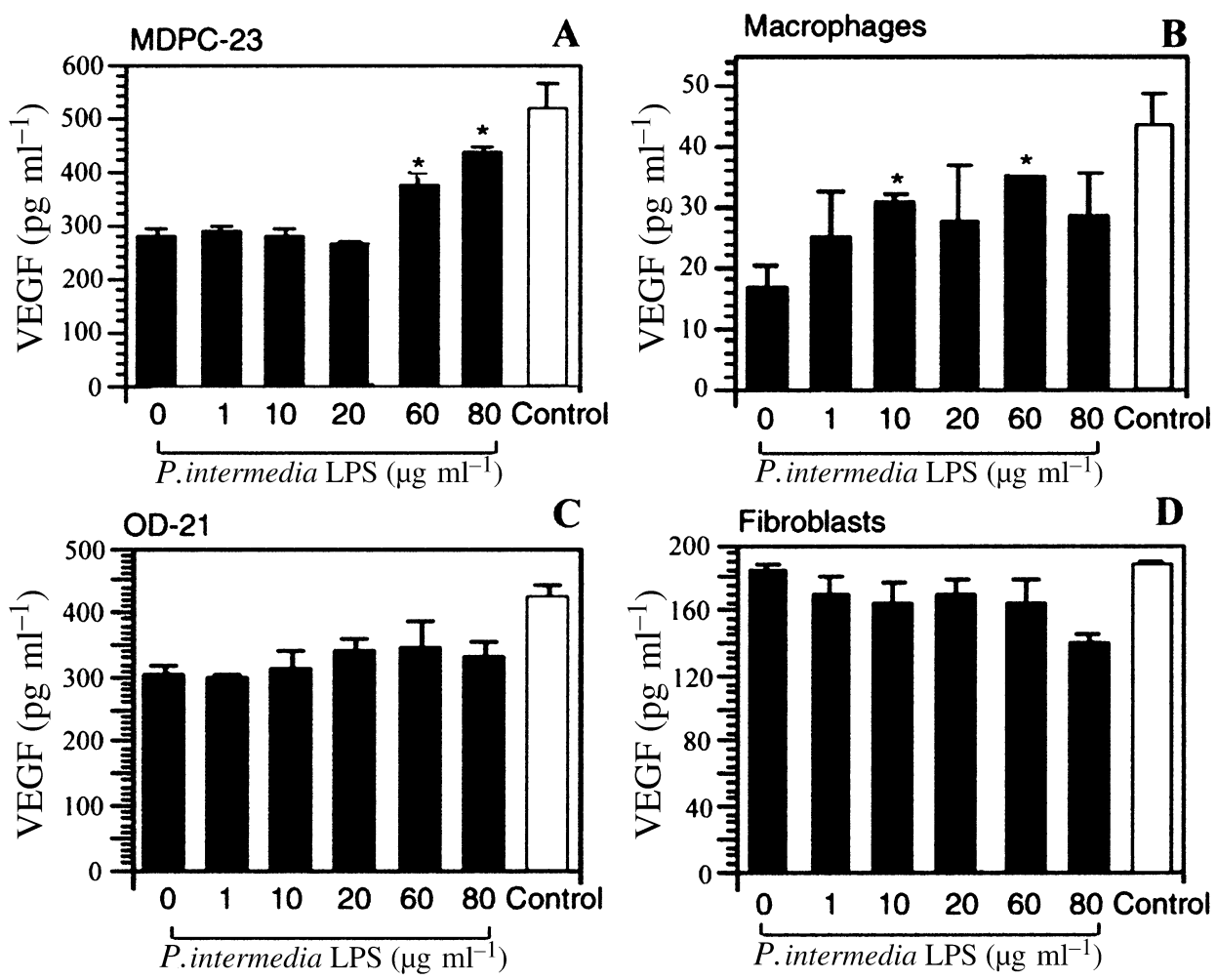

Fig. 3. Prevotella intermedia lipopolysaccharide (LPS) induces vascular endothelial growth factor (VEGF) expression in odontoblast-like cells (MDPC-23) and macrophages. Expression of VEGF was analysed by enzyme-linked immunosorbent assay (ELISA) of conditioned medium from (A) MDPC-23, (B) macrophages, (C) OD-21, or (D) gingival fibroblasts exposed for $24 \mathrm{~h}$ to $0-80 \mu \mathrm{g} \mathrm{ml} \mathrm{l}^{-1}$ of $P$. intermedia LPS. Positive control for ELISA was recombinant mouse VEGF. ${ }^{*}, P \leq 0.05$.

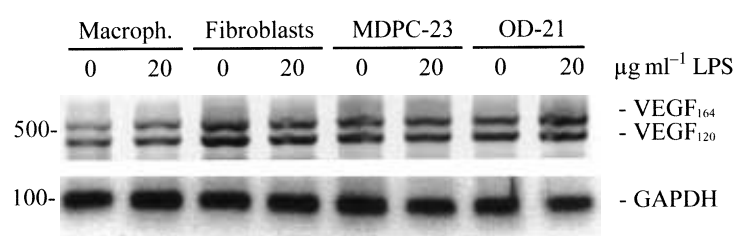

Fig. 4. Vascular endothelial growth factor (VEGF) mRNA expression is not affected by lipopolysaccharide (LPS) stimulation. Reverse transcriptase polymerase chain reaction (RT-PCR) for VEGF performed on MDPC-23, OD-21, gingival fibroblasts and macrophages exposed for $24 \mathrm{~h}$ to 0 or $20 \mu \mathrm{g} \mathrm{ml}^{-1}$ Escherichia coli LPS. Glyceraldehyde adenosinephosphate dehydrogenase (GAPDH) was used as internal control for RT-PCR assay.

cells were exposed to at least $60 \mu \mathrm{g} \mathrm{ml}^{-1}$ LPS (Fig. 3A). We also observed a tendency towards upregulation of VEGF expression in macrophages exposed to $P$. intermedia LPS (Fig. 3B). In contrast, we did not observe any upregulation of VEGF expression in OD-21 (Fig. 3C) or fibroblasts (Fig. 3D) stimulated with P. intermedia LPS.

\section{Lipopolysaccharide-induced VEGF expression is regulated at post-transcriptional level}

To examine if LPS-induced VEGF expression is regulated primarily at the transcriptional or at the post- transcriptional level, we performed semiquantitative RT-PCR analysis. The PCR primers used here were designed to amplify all three mouse VEGF isoforms (32). However, we only observed bands for the $\mathrm{VEGF}_{120}$ and VEGF $_{164}$ isoforms in the cells evaluated in our study. These findings might be explained by the fact that these two are the most predominant VEGF isoforms in mice (31). We observed that the VEGF mRNA expression is lower in macrophages compared with MDPC-23, OD-21, or fibroblasts (Fig. 4). Interestingly, E. coli LPS did not induce any significant change in VEGF expression at the mRNA level in the cell lines evacuated here (Fig. 4).

\section{Macrophages exposed to LPS present cytoplasmic elongations}

Macrophage stimulation with $P$. intermedia LPS (Fig. 5B) or E. coli LPS (data not shown) induced consistent changes in cell morphology. The majority of the macrophages became enlarged with short cytoplasmic elongations, suggesting a process of cellular activation mediated by LPS (Fig. 5A,B). In contrast, fibroblasts (Fig. 5C,D), MDPC-23 (Fig. 5E,F), and OD-21 (Fig. 5G,H) did not show any detectable change in morphology compared with untreated cells when examined by phase contrast microscopy at $\times 400$. 

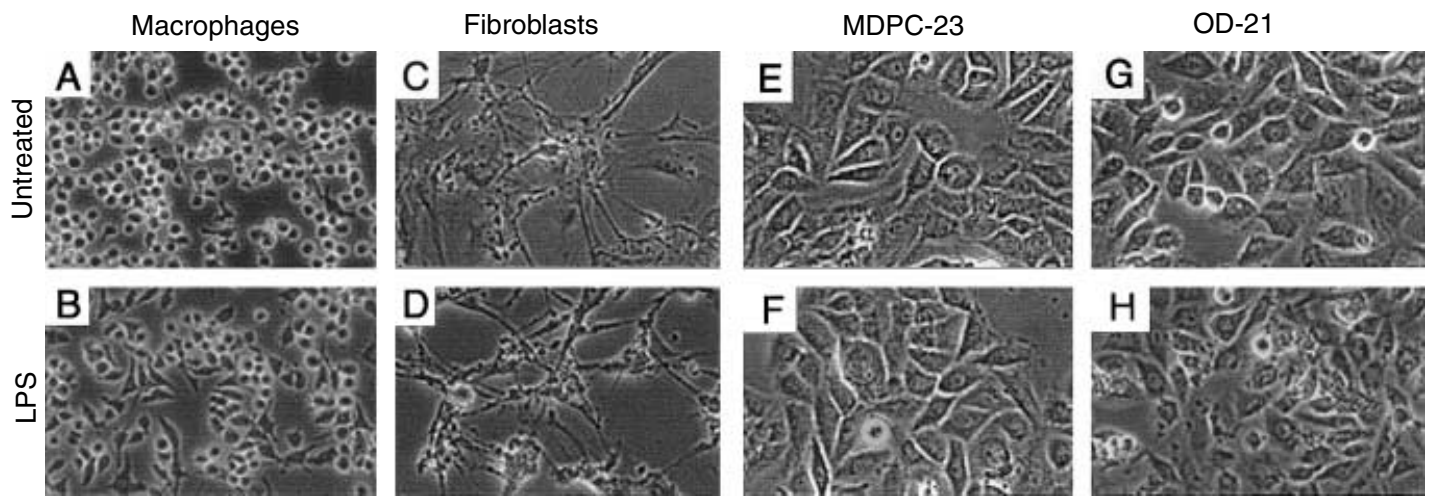

Fig. 5. Macrophages exposed to lipopolysaccharide (LPS) present cytoplasmic elongations. Micromorphology of (A,B) macr-

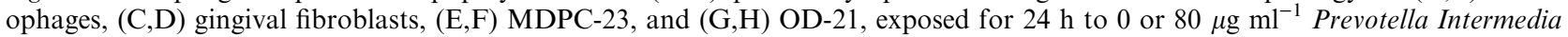
LPS. Phase-contrast photomicrographs at $\times 400$.

\section{Discussion}

Vascular endothelial growth factor is one of the major regulators of neovascular responses throughout the body, but its function in the dental pulp is still largely unknown. This study was designed to investigate the relative levels of VEGF synthesis in MDPC-23, OD-21, gingival fibroblasts, and macrophages exposed to LPS, and to provide insights into the mechanism involved in LPS-induced VEGF expression in these cells. We observed that MDPC23 and macrophages showed upregulation of VEGF expression upon stimulation with LPS. In contrast, LPS did not enhance VEGF expression in mouse OD-21 cells or in gingival fibroblasts. A comparative analysis of RT-PCR and ELISA data suggested that VEGF is regulated primarily at the post-transcriptional level.

The odontoblast-like cells (MDPC-23) and undifferentiated pulp cells (OD-21) used in this study were cells spontaneously immortalized from $\mathrm{CD}-1$ fetal mouse molar papillae (33). The MDPC-23 cells express dentin phosphophoryn (DPP) and dentin sialoprotein (DSP), while OD-21 cells do not express these markers of odontoblastic activity (33). We believe that an important finding of our study is the high baseline level of VEGF expression observed in untreated odontoblast-like cells and undifferentiated pulp cells. Untreated MDPC-23 and OD-21 expressed, respectively, approximately 14 and 25 times more VEGF than untreated macrophages. The relevance of this observation is perhaps demonstrated by the fact that macrophages are considered to be key orchestrators of neovascularization during wound healing and several angiogenesis-dependent diseases (34). The presence of capillary loops in secreting odontoblast layers provides access of nutrients and minerals to the calcifying front and allows for the deposition of secondary dentin $(35,36)$. Interestingly, our in vitro findings are in agreement with a previous report that showed expression of VEGF in healthy pulps of non-carious teeth without signs of inflammation by immunohistochemistry (28). Furthermore, our data suggest that odontoblasts and undifferentiated pulp cells are important cellular sources of VEGF in the dental pulp. We speculate that the relatively high levels of VEGF secreted by unstimulated pulp cells provide a pro-angiogenic input that is necessary for the maintenance of pulp vascularization.

The expression of VEGF in the dentin matrix reported recently by ROBERTS-CLARK \& SMITH (26) suggests that VEGF was also present during dentinogenesis. Importantly, the authors propose that the dentin matrix VEGF could be released during caries progression and contribute to reparative responses of the dentin-pulp complex. Here, we identified the odontoblasts and macrophages as additional sources of the VEGF that might be involved in the orchestration of the pro-angiogenic responses observed in the pulp of carious teeth. We observed that odontoblast-like cells and macrophages, but not undifferentiated pulp cells, exposed to bacterial LPS consistently upregulate VEGF synthesis. While the results obtained from cell lines should be interpreted with caution, our experiments confirmed a previous report that demonstrated that VEGF was up-regulated in a mixed population of human dental pulp cells exposed to LPS (27), and suggest that odontoblasts and macrophages may be the cell populations responsible, in part, for the previously reported upregulation of VEGF expression induced by LPS.

The observation that odontoblast-like cells stimulated by LPS upregulate VEGF expression suggests a novel role for odontoblasts in pulp biology, i.e. regulation of pulpal angiogenesis. Odontoblasts are considered to be one of the first cell populations to sense the bacterial challenge that occurs during the progress of dentinal caries (1). We propose that upregulated VEGF synthesis by odontoblasts stimulated with LPS might have two functions. (a) To increase the permeability of existing pulp blood vessels. VEGF-induced microvessel permeability is known to facilitate the process of diapedesis of neutrophils, lymphocytes, and monocytes (25). This would allow for the establishment of cellular defenses to protect the pulp tissue against the bacterial challenges resulting from caries progression. (b) To recruit new blood vessels to the area closest to the carious lesion. This would enhance the access of the blood-derived antibodies and defense cells to protect the pulp tissue against bacterial challenges $(3,37)$. 
Macrophages exposed to bacterial LPS also showed upregulation in VEGF expression. The VEGF upregulation in macrophages exposed to bacterial LPS reported here corroborates findings published elsewhere (38-40) and are in agreement with the observation that VEGF is strongly expressed in cells of the inflammatory infiltrate of teeth with irreversible pulpitis (28). Macrophages challenged with bacterial LPS were enlarged and presented short cytoplasmic elongations compared with smaller and round, untreated macrophages. These morphological changes might be correlated with the complex process of macrophage activation observed upon stimulation by bacterial products (41).

Prevotella intermedia have been associated with the process of dentinal caries (10), irreversible pulpitis (12), and endodontic infections $(42,43)$. The data presented here showed that $P$. intermedia LPS induced a similar trend of VEGF induction to E. coli LPS, but it required higher concentrations of LPS. In the current study, $0-20 \mu \mathrm{g} \mathrm{ml}^{-1}$ E. coli LPS or $0-80 \mu \mathrm{g} \mathrm{ml}^{-1} P$. intermedia LPS were used to challenge the cells. Other studies have used a range of $0.01-100 \mu \mathrm{g} \mathrm{ml}^{-1}$ LPS $(27,44)$, which is believed to be within a range of LPS relevant to pulp pathologies (45). A previous investigation has evaluated the effect of LPS from Porphyromonas endodontalis, Porphyromonas gingivalis, Fusobacterium nucleatum, and E. coli on DNA content, protein synthesis, and alkaline phosphatase activity in dental pulp cells (44). The authors found a similar trend for the effect of LPS from these bacterial species on DNA content and protein synthesis, however, E. coli LPS seemed to elicit the most intense responses (44). We speculate that the differences in reactivity between $E$. coli and $P$. intermedia LPS might arise from their molecular specificity to cell receptors, or differences in the chemical structure of the lipid A portion of the LPS molecule, which has been shown to affect the intensity of responses in other systems $(17,46)$.

Baseline VEGF mRNA expression was lowest in macrophages, which was in agreement with our ELISA data. Interestingly, there were no significant changes in VEGF mRNA levels, compared with untreated control cells, when MDPC-23 or macrophages were exposed to LPS. It was previously reported that VEGF regulation occurs primarily at the level of mRNA stability, since ubiquitination of its $3^{\prime} \mathrm{UTR}$ is impaired when proangiogenic stimuli are present (47). Our data corroborate the study that was performed in rat heart myocytes (47) and indicate that the regulation of LPS-induced VEGF expression in MDPC-23 and macrophages also happens primarily at the post-transcriptional level.

In summary, the data presented here demonstrates that non-stimulated mouse dental pulp cells secrete high levels of the pro-angiogenic VEGF protein. Interestingly, the odontoblast-like cells and macrophages, but not undifferentiated pulp cells or fibroblasts, upregulated VEGF protein expression in response to LPS stimulation. This demonstrates that the ability to respond to LPS stimulation and enhance VEGF expression is specific to certain cell types, and not a generalized cellular response. The results require rejection of the test hypothesis that all cells increase VEGF expression following exposure to LPS. We hypothesize that odontoblasts and macrophages are key orchestrators of pulp neovascularization in teeth with deep carious lesions. In vivo models of pulp angiogenesis are currently being used to test this hypothesis.

Acknowledgments - We thank C. E. Shelburne for his generous gift of $P$. intermedia LPS and for reviewing this manuscript, and D. Chiego for fruitful discussions and expert advice. This study was supported by start-up funds from the Department of Cariology, Restorative Sciences, and Endodontics, University of Michigan School of Dentistry (to J.E.N.).

\section{References}

1. Pashley DH. Dynamics of the pulpo-dentin complex. Crit Rev Oral Biol Med 1996; 7: 104-133.

2. Takahashi K. Pulpal vascular changes in inflammation. Proc Finn Dent Soc 1992; 88: 381-385.

3. Kim S, Lui M, Simchon S, Dorscher-Kim JE. Effects of selected inflammatory mediators on blood flow and vascular permeability in the dental pulp. Proc Finn Dent Soc 1992; 88: 387-392.

4. Heyeraas J, Kvinnsland I. Tissue pressure and blood flow in pulpal inflammation. Proc Finn Dent Soc 1992; 88: 393-401.

5. Seltzer S, Farber PA. Microbiologic factors in endodontology. Oral Surg Oral Med Oral Pathol 1994; 78: 634-645.

6. Loesche WJ, Syed SA. The predominant cultivable flora of carious plaque and carious dentine. Caries Res 1973; 7: 201216.

7. Rølla G, Oppermann RV, Bowen WH, Ciardi JE, Knox KW. High amounts of lipoteichoic acid in sucrose-induced plaque in vivo. Caries Res 1980; 14: 235-238.

8. GinsBurg I. Role of lipoteichoic acid in infection and inflammation. Lancet Infect Dis 2002; 2: 171-179.

9. Hoshino E. Predominant obligate anaerobes in human carious dentin. J Dent Res 1985; 64: 1195-1198.

10. Massey WlK, Romberg DM, Hunter N, Hume WR. The association of carious dentin microflora with tissue changes in human pulpitis. Oral Microbiol Immun 1993; 8: 30-35.

11. Love RM, JENKINSON HF. Invasion of dentinal tubules by oral bacteria. Crit Rev Oral Biol Med 2002; 13: 171-183.

12. Hahn CL, FAlKLer WA, Minah GE. Microbiological studies of carious dentine from human teeth with irreversible pulpitis. Arch Oral Biol 1991; 36: 147-153.

13. Hosoya S, Matsushima K. Stimulation of interleukin- $1 \beta$ production of human dental pulp cells by Porphyromonas endodontalis lipopolysaccharides. J Endodont 1997; 23: 39-42.

14. Tokuda M, Sakuta T, Fushuku A, Torit M, Nagaoka S. Regulation of interleukin-6 expression in human dental pulp cell cultures stimulated with Prevotella intermedia lipopolysaccharide. J Endodont 2001; 27: 273-277.

15. Nagaoka S, Tokuda M, Sakuta T, Taketoshi Y, Tamura M, TAKADA H, KAWAGOE M. Interleukin-8 gene expression by human dental pulp fibroblast in cultures stimulated with Prevotella intermedia lipopolysaccharide. J Endodont 1996; 22: 9-12.

16. Rietschel et, Kirikae T, Schade FU, Ulmer AJ, Halst O, Brade H, Schmidt G, Mamat U, Grinmecke HD, Kusumoto $\mathrm{S}$. The chemical structure of bacterial endotoxin in relation to bioactivity. Immunobiology 1993; 187: 169-190.

17. Nester EN, Anderson DG, Roberts CE, Pearsall NN, Nester MT. Microbiology: a human perspective, 3rd edn. New York: McGraw-Hill, 2001; 61-66.

18. GUHA M, MACKMAN N. LPS induction of gene expression in human monocytes. Cell Signaling 2001; 13: 85-94.

19. Takeuchi O, AkiRa S. Toll-like receptors; their physiological role and signal transduction system. Int Immunopharmacol 2001; 14: 625-635. 
20. DZiarski R, Gupta D. Role of MD-2 in TLR2- and TRL4mediated recognition of Gram-negative and Gram-positive bacteria and activation of chemokine genes. $J$ Endotoxin Res 2000; 6: 401-405.

21. Horng T, Barton GM, Medzhitov R. Tirap. an adapter molecule in the toll-signaling pathway. Nat Immunol 2001; 2: 835-841.

22. Ferrara N. Vascular endothelial growth factor. Eur J Cancer 1996; 32A: 2413-2422.

23. Polverini PJ. The pathophysiology of angiogenesis. Crit Rev Oral Biol Med 1995; 6: 230-247.

24. Nör JE, Christensen J, Mooney DJ, Polverini PJ. Vascular endothelial growth factor (VEGF)-mediated angiogenesis is associated with enhanced endothelial cell survival and induction of Bcl-2 expression. Am J Pathol 1999; 154: 375-384.

25. Dvorak HF, Brown LF, Detmar M, Dvorak AM. Vascular permeability factor/vascular endothelial growth factor, microvascular hyperpermeability, and angiogenesis. Am J Pathol 1995; 146: 1029-1039.

26. Roberts-Clark DJ, Smith AJ. Angiogenic growth factors in human dentine matrix. Arch Oral Biol 2000; 45: 1013-1016.

27. Matsushita K, Motani R, Sakuta T, Nagaoka S, Matsuyama T, Abeyama K, Maruyama H, Takada H, Toril M. Lipopolysaccharide enhances the production of vascular endothelial growth factor by human pulp cells in culture. Infect Immun 1999; 67: 1633-1639.

28. Artese L, Rubini C, Ferrero G, Fioroni M, Santinelli A, Piattelli A. Vascular endothelial growth factor (VEGF) expression in healthy and inflamed human dental pulps. $J$ Endodont 2002; 28: 20-23.

29. Hanks CT, Sun ZL, Fang DN, Edwards CA, Wataha JC, Ritchie HH, Butler WT. Cloned 3T6 cell line from CD-1 mouse fetal molar dental papillae. Connect Tissue Res 1998; 37: 233-249.

30. FreshnEY R. Culture of animal cells: a manual of basic techniques, 3rd edn. Hoboken: Wiley Higher Education, 1993.

31. Shima TD, Kuroki M, Deutsch U, NG Y-S, Adamis AP, D'AMORES PA. The mouse gene for vascular endothelial growth factor. J Biol Chem 1996; 271: 3877-3883.

32. Hovey RC, Goldhar AS, Baffi J, Vonkerhaar BK. Transcriptional regulation of vascular endothelial growth factor expression in epithelial and stromal cells during mouse mammary gland development. Mol Endocrinol 2001; 15: 819-883.

33. Hanks CT, Fang D, Sun Z, Edwards CA, Butler WT. Dentin-specific proteins in MDPC-23 cell line. Eur J Oral Sci 1998; 106: 260-266.
34. Polverini PJ. Role of the macrophage in angiogenesisdependent diseases. In: Golberg ID, Rosen EM, eds. Regulation of angiogenesis. Basel: Birkhäuser-Verlag 1997, 11-28.

35. Yoshida S, Ohshima H. Distribution and organization of peripheral capillaries in dental pulp and their relationship to odontoblasts. Anat Rec 1996; 245: 313-326.

36. Tabata S, Wada K, Semba T. Fate of odontoblasts and blood capillaries in the incisal region of the rat incisor pulp. Anat Rec 1993; 235: 12-20.

37. Okiji T, Morita I, Sunada I, Murota S. Involvement of arachidonic acid metabolites in increase in vascular permeability in experimental dental pulpal inflammation in the rat. Arch Oral Biol 1989; 34: 523-528.

38. Itaya H, Imaizumi $\mathrm{T}$, Yoshida $\mathrm{H}$, Koyoma M, Suzuki S, SATOH K. Expression of vascular endothelial growth factor in human monocyte/macrophages stimulated with lipopolysaccharides. Thromb Haemost 2001; 85: 171-176.

39. Sakuta T, Matsushita K, Yamaguchi N, Oyama T, Motani R, Koga T, Nagaoka S, Abeyama K, Maruyama I, Takada H, Tori M. Enhanced production of vascular endothelial growth factor by human monocytic cells stimulated with endotoxin through transcription factor SP-1. J Med Microbiol 2001; 50: 233-237.

40. Xiong M, Elson G, Legarda D, Leibovich SJ. Production of vascular endothelial growth factor by murine macrophages. $\mathrm{Am}$ J Pathol 1998; 153: 587-598.

41. Ross HM, Romrell LJ, Kaye GI. Histology: a text and atlas, 3rd edn. Baltimore: Williams \& Wilkins 1995; 107-110.

42. Bae KS, Baumgartner JC, Shearer TR, David LL. Occurrence of Prevotella nigrescens and Prevotella intermedia in infections of endodontic origin. $J$ Endodont 1997; 23: $620-623$.

43. SundQvist G. Taxonomy, ecology and pathogenicity of the root canal flora. Oral Surg Oral Med Oral Pathol 1994; 78: 522 530.

44. Nakane A, Yoshida T, Nakata K, Horiba N, Nakamura H. Effects of lipopolysaccharides on human dental pulp cells. J Endodont 1995; 21: 128-130.

45. Horiba N, Maekawa Y, Matsumoto T, Nakamura H. A study of the distribution of endotoxin in the dentinal wall of infected root canals. J Endodont 1990; 16: 331-334.

46. DaRveAu RP. Lipid A diversity and the innate host response to bacterial infection. Curr Opin Microbiol 1998; 1: 36-42.

47. Levy AP, Levy NS, Goldberg MA. Post-transcriptional regulation of vascular endothelial growth factor by hypoxia. J Biol Chem 1996; 271: 2746-2753. 